\title{
In situ X-ray Diffraction during Casting: Study of Hot Tearing in Al-Zn alloys
}

\author{
Jean-Marie Drezet ${ }^{*}$, Bastien Mireux and Guven Kurtuldu \\ Computational Materials Laboratory, Ecole Polytechnique Federale Lausanne, station 12, Lausanne \\ $\mathrm{CH}-1015$, Switzerland \\ Corresponding author: jean-marie.drezet@epfl.ch
}

Keywords: solidification, aluminum alloys, rigidity temperature, in situ X-Ray diffraction

\begin{abstract}
During solidification of metallic alloys, coalescence corresponds to the formation of solid bridges between grains when both solid and liquid phases are percolated. As such, it represents a key transition with respect to the mechanical behaviour of solidifying alloys and to the prediction of solidification cracking. Coalescence starts at the coherency point when the grains begin to touch each other, but are unable to sustain any tensile loads. It ends up at the rigidity temperature when the solid phase is sufficiently coalesced to transmit macroscopic tensile strains and stresses. This temperature, also called mechanical or tensile coherency temperature, is a major input parameter in numerical modelling of solidification processes as it defines the point at which thermally induced deformations start to generate internal stresses in a casting. The rigidity temperature has been determined in $\mathrm{Al} \mathrm{Zn}$ alloys using in situ X-ray diffraction (XRD) during casting in a dog bone shaped mould. This set-up allows the sample to build up internal stress naturally as its contraction is prevented. The cooling on both extremities of the mould induces a hot spot at the middle of the sample which is irradiated by X-rays. Diffraction patterns were recorded every $0.5 \mathrm{~s}$ using a detector covering a $426 \mathrm{x} 426 \mathrm{~mm}^{2}$ area. The change of diffraction angles allowed us to observe agglomeration/decohesion of growing grain clusters and to determine a solid volume fraction at rigidity around $98 \%$ depending on solidification time for grain refined $\mathrm{Al} 6.2 \mathrm{wt} \% \mathrm{Zn}$ alloys.
\end{abstract}

\section{Introduction}

Coalescence corresponds to the formation of solid bridges between grains when both solid and liquid phases are percolated [1]. As such, it represents a key transition in the solidification of metallic alloys. Coalescence starts at the coherency point when the grains begin to touch each other, but are unable to sustain any tensile loads. Rappaz et al. [2] have used the concept of disjoining-pressure used in fluid dynamics to establish a theoretical framework for the coalescence of primary phase dendritic arms within a single grain or at grain boundaries. The authors have shown that for pure substances, approaching planar liquid/solid interfaces coalesce to a grain boundary at an undercooling $\Delta \mathrm{T}_{\mathrm{b}}$ that is proportional to the difference between the grain boundary energy and two times the solid/liquid interfacial energy [2]. The latter quantity depends on the grain misorientation. When it is positive, the two liquid/solid interfaces are "repulsive." In this case, a stable liquid film between adjacent dendrite arms located across such grain boundaries can remain until the undercooling exceeds $\Delta \mathrm{T}_{\mathrm{b}}$.

For alloys, coalescence is also influenced by the concentration of solute elements in the liquid films [2]. The temperature and concentration of the liquid films must reach a coalescence line parallel to, but $\Delta \mathrm{T}_{\mathrm{b}}$ below, the liquidus line before coalescence can occur.

At the macroscopic level, i.e., at the level of many randomly oriented grains, coalescence must be considered as a transition taking place between coherency (first contact between the grains) and rigidity (ability to transmit tensile strains and stresses). If coalescence between some grains is slowed down, i.e., finishes at lower temperatures, the mushy structure becomes particularly sensitive to hot tearing or solidification cracking [3]. This defect is a spontaneous failure of semi-solid metallic alloys that results in an intergranular fracture profile. It forms during casting near the end of solidification where straining becomes localized and local liquid permeability is very low. Coalescence ends at the rigidity point when the structure is able to sustain substantial tensile strains and stresses, i.e., when the 
solid phase is sufficiently percolated. The rigidity temperature is important as it determines the very instant macroscopic stresses start to build up owing to thermally induced deformations [4]. It is an important input data for numerical modeling of as-cast residual stresses in billets and rolling sheet ingots as it dictates the temperature below which thermal strains start to occur.

The mechanical behavior of alloys in the mushy state has recently been intensively studied using $\mathrm{X}$-ray microtomography [5-11]. In one study, in situ tensile test experiments were performed by Terzi et al. [5,6] on Al-Cu alloys in the mushy state at the European Synchrotron Radiation Facility (ESRF). The major drawbacks of such in situ tensile tests are that they are carried out in isothermal conditions, and not during rapid cooling, since the time resolution for X-ray micro tomography imaging is often limited [7]. Moreover, the exact mechanical loading within the material is not known as the deformation, localized in the hottest part of the specimen, is not measured. These tests are presently limited to Al-Cu alloys [8] in order to get a good contrast between the liquid and solid phases, and the alloy is tested after heating to the correct temperature within the solidification interval and not during solidification from the fully liquid state. The last point is particularly detrimental as solidifying microstructures are different from those obtained after heating owing to dendrite coarsening and redistribution of solute elements [9].

In situ studies of stress accumulation in solidifying metals are rather limited although many stress measurements have been carried out post mortem. Drezet et al. have used neutron diffraction to measure post mortem internal stresses in as-cast billet [12] and ingots [13] and as-quenched thick plates [14] and forgings [15]. With these studies, neutron diffraction at high flux sources appeared to be particularly well suited for stress measurements in aluminum alloys as this metal is very transparent to neutrons. Neutrons were then used to determine in situ the very moment when macroscopic strains and stresses appear in the mushy alloy [16]. As one diffraction peak was recorded only every $11 \mathrm{~s}$, the cooling rate was reduced and rigidity temperatures were measured in grain refined $\mathrm{Al}-\mathrm{Cu}$ alloys. The hot tearing tendency was linked with the rigidity temperature, the cooling rate and the degree of grain refinement.

In the present study, X-ray diffraction has been performed in situ during solidification with a higher time resolution at the I12 high-energy beamline at the Diamond Light Source, UK [17]. Rigidity temperature has been measured in Al-Zn alloys under various cooling regimes in a dog bone shaped mould similarly to the neutron experiments, where solidification and tensile straining are concomitant. Al Zn alloys are particularly interesting as they are the base of the 7xxx aluminium alloys series. Those alloys are known to be very sensitive to hot cracking [18] owing to their long freezing range.

\section{In situ X-ray diffraction during casting}

\subsection{Materials and castings}

Al-5 $\mathrm{wt} \% \mathrm{Zn}$ alloys were prepared by melting high purity aluminium and pure zinc in a stainless steel crucible at $720{ }^{\circ} \mathrm{C}$. The alloys were then grain refined with $0.4 \mathrm{wt} \% \mathrm{Al}-\mathrm{TiB}_{2}$ master alloy. The casting into a dog bone shape mould with water-cooled extremities and subsequent solidification was carried out in sync with the in-situ acquisition of X-ray diffraction patterns. The mould, shown in Figure 1, is usually used to study the hot tearing susceptibility of new alloys. A hot spot forms at the center of the casting and its axial contraction is prevented by the steel central part. The thermal contraction of the solidifying material is constrained and stresses developing at the hot spot may lead to hot cracking. The major advantage of this configuration is that solidification and tensile straining are concomitant. The amount of straining on the hot spot is controlled by modulating cooling of the mould extremities, by preheating the mould with electric heating elements and by changing the length of the central part of the mould, i.e. by changing the amount of straining that is localized at the hot spot [16]. 

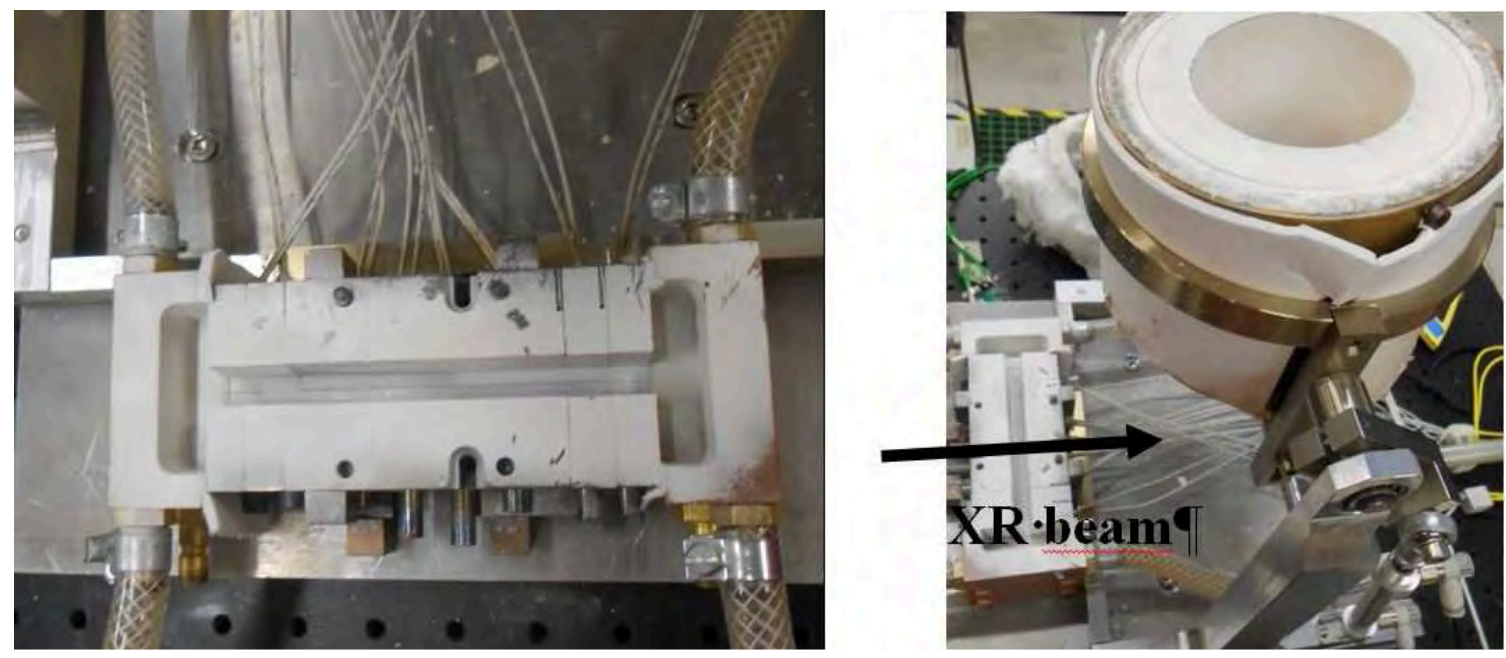

Figure 1: Dog bone shape mould (left) and tilting crucible holder. The XR beam traversing the casting is schematically shown.

\section{2 in situ X-ray diffraction}

In order to measure the accumulation of elastic strain and thus of stress during casting, the lattice spacing was measured in situ at the hot spot location using X-ray diffraction. Small conical holes were machined in the steel mould to provide unimpeded access to the sample for the X-ray beam. Insulating alumina muffles were used to plug these holes to avoid any liquid metal leakage. As shown in fig. 1 right, the crucible was mounted on a tilting support, in order to control the pouring remotely by a pneumatic pusher. This allowed us to synchronize the onset of the acquisition of diffraction data precisely with the process of pouring.

Six type K thermocouples arrayed along the sample axis within the casting allowed linking the temperature within the gauge volume with the formation and shift of the diffraction peaks during solidification. Precisely, one $\phi=0.5 \mathrm{~mm}$ thermocouple was partially in the gauge volume. The monochromatic $60.07 \mathrm{keV}$ X-ray diffraction patterns were acquired using a 2D flat panel detector covering a $426 \times 426 \mathrm{~mm}^{2}$ area. The pixel size was $148 \mu \mathrm{m}$ in each direction, and the sample-to-detector distance was $1299 \mathrm{~mm}$, measured from the middle of the sample. The beam size was $0.5 \times 0.5 \mathrm{~mm}$ and the sample thickness was $7.5 \mathrm{~mm}$ in the gauge volume in order to minimize ring broadening. The acquisition of both temperature and diffraction patterns was synchronized and recorded at a continuous acquisition rate of $2 \mathrm{~Hz}$.

\section{Results}

\subsection{Al-Zn castings, microstructure and solidification path}

Three dog bone (DB) shaped samples of identical length have been casted. In the following they are referred to as DB1, DB2 and DB3. No cracks were visible on sample DB2 and small hot tears were visible at the surface of samples DB1 and DB3. Sample DB3 presented a crack at the location of the central thermocouple as shown in figure 2. Thermocouples are known to promote initiating hot tears [1]. Dye penetrant tests conducted after the in-situ diffraction experiment revealed that all three samples contained tiny hot tears at their surface. 


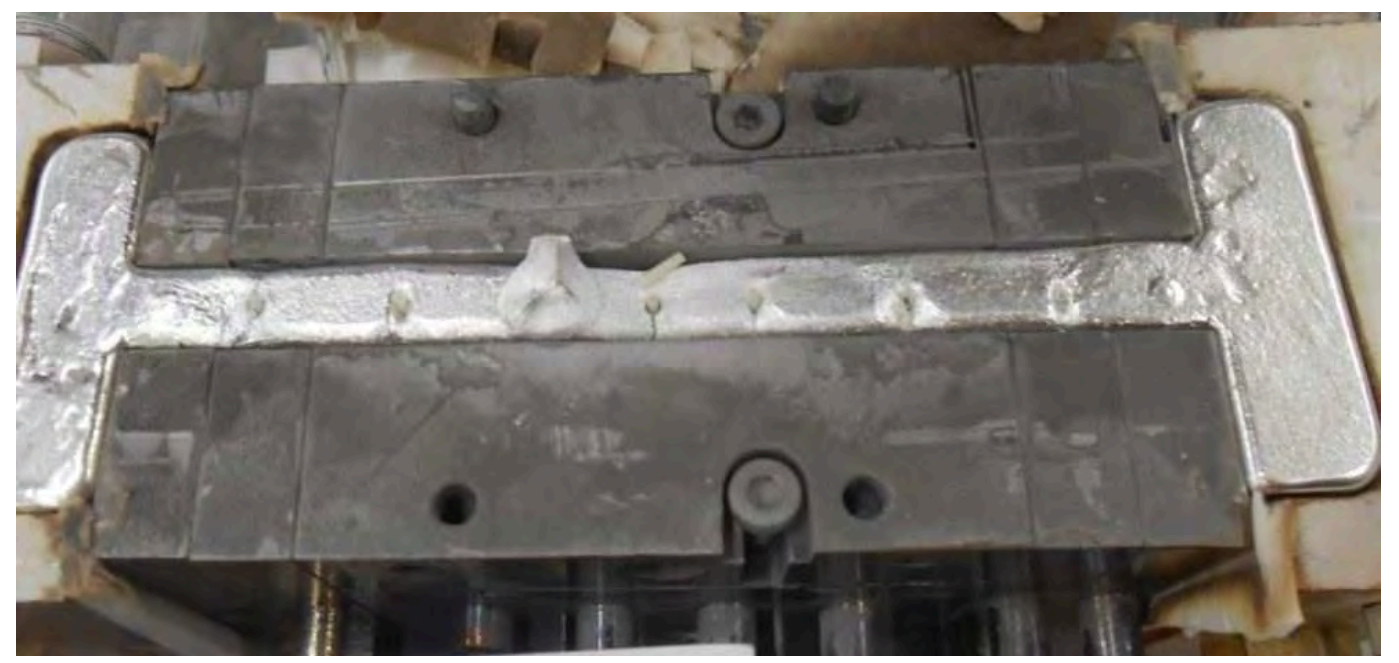

Figure 2: Sample DB3 showing a crack formed at the location of the thermocouple.

Figure 3 shows scanning electron microscopy (SEM) micrographs of sample DB3. The secondary electron mode was used to see solute rich grain boundaries and intergranular microsegregation. The microstructure is globular as a result of both the use of grain refiner $\left(0.4 \mathrm{wt} . \% \mathrm{AlTiB}_{2}\right)$ and a rather high cooling rate. An average grain size of $120 \mu \mathrm{m}$ is determined and the $\mathrm{Al} \mathrm{Zn}$ eutectic is clearly visible at grain boundaries meaning that the solidification ends with the eutectic transformation at $381^{\circ} \mathrm{C}$ [17]. Some micropores and tiny hot tears are also visible at triple grain junctions. Similar defects were observed in samples DB1 and DB2.
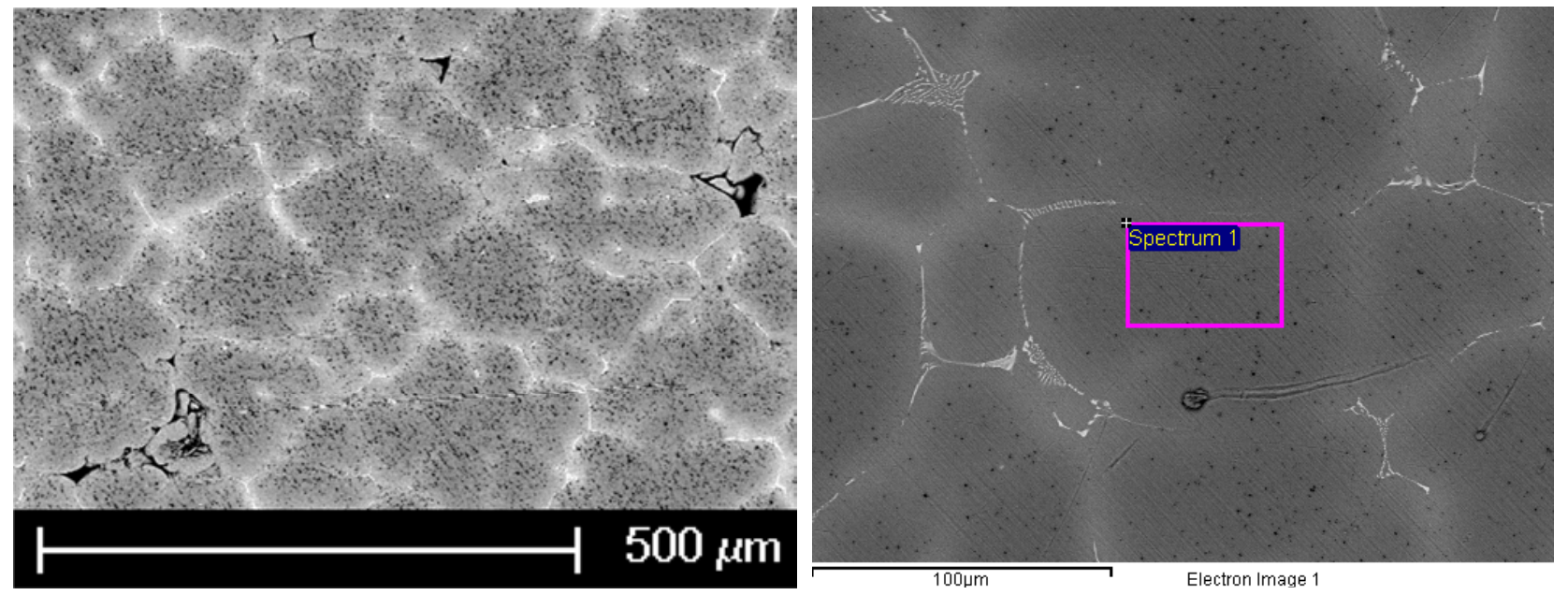

Figure 3: left, SEM micrograph of the Al Zn sample DB3 using secondary electron mode and right, zoomed in region showing the formation of $\mathrm{Al} \mathrm{Zn}$ eutectic at grain boundaries.

\subsection{Temperature measurements and solidification path}

Figure 4 shows the temperature recorded at the hot spot location for the three castings. The liquid metal temperature varied from $690{ }^{\circ} \mathrm{C}$ to $755^{\circ} \mathrm{C}$ and the initial mould temperature from $440{ }^{\circ} \mathrm{C}$ to 540 ${ }^{\circ} \mathrm{C}$, thus giving different cooling's. Two samples, DB 1 and 3 exhibit a similar cooling path with whereas sample DB 2 solidifies much slowly. As soon as the alloy starts to solidify, latent heat is released and the temperature exhibits a plateau. This allows reading liquidus temperatures for the three castings around $650^{\circ} \mathrm{C} \pm 0.5^{\circ} \mathrm{C}$ indicating a $\mathrm{Zn}$ content of $6.2 \mathrm{wt} \%$ according to the $\mathrm{Al}-\mathrm{Zn}$ phase diagram. Samples were prepared with $5 \mathrm{wt} \%$ of $\mathrm{Zn}$ and this discrepancy is explained from macrosegregation taking place at the length scale of the casting Indeed, during casting solute cumulates ahead the two solidification fronts advancing from both mould extremities enriching the liquid at the hot spot. Solidification times for the transition from liquidus and eutectic are comparable for samples DB1 and DB3 (76 s and $97 \mathrm{~s}$ ) but are much longer for DB2 (373 s). This is attributed to the lower initial mould temperature for these two castings $\left(480^{\circ} \mathrm{C}\right.$ and $\left.468^{\circ} \mathrm{C}\right)$ compared to sample 
DB2 $\left(540^{\circ} \mathrm{C}\right)$. The average cooling rate experienced by each sample is calculated as the ratio between non equilibrium solidification interval, $269^{\circ} \mathrm{C}$, and the corresponding solidification time. In samples DB1 and DB3 the cooling rate is rather close to $-3 \mathrm{~K} / \mathrm{s}$ whereas sample DB2 exhibits an average cooling rate of $-0.7 \mathrm{~K} / \mathrm{s}$.

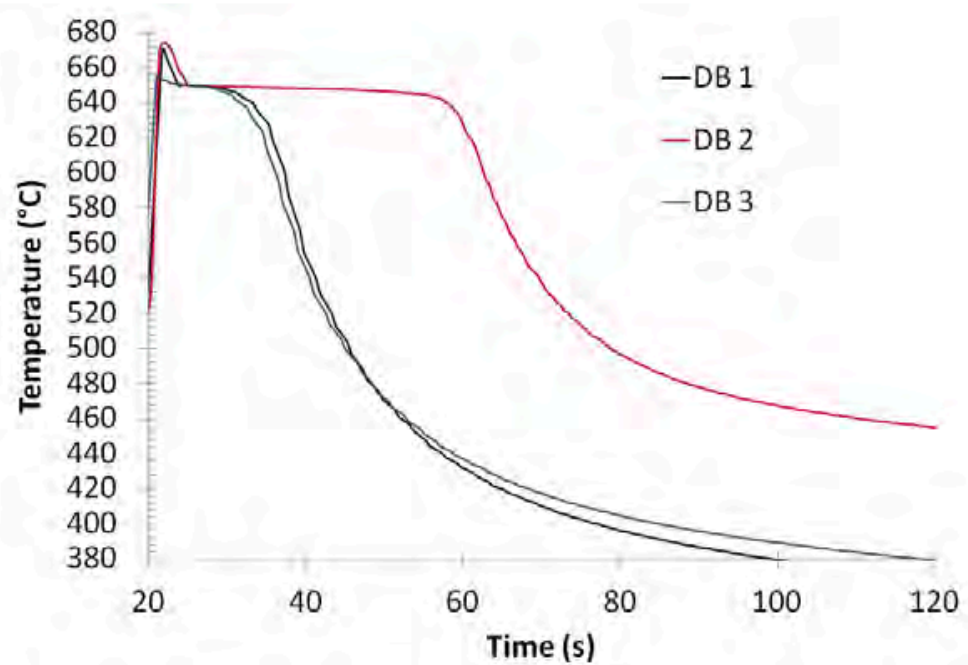

Figure 4: Temperature versus time at the hot spot for the three samples.

The temperature evolution of the sample during solidification is used to calculate the volume fraction of solid, $\mathrm{g}_{\mathrm{s}}$, during solidification. To do so, the thermodynamic phase diagram of the binary system $\mathrm{Al} \mathrm{Zn}$ is required. Figure 5 shows this phase diagram [19]. The eutectic temperature is $381^{\circ} \mathrm{C}$ with a $\mathrm{Zn}$ content of $95 \mathrm{wt} \%$ in the liquid phase. As the partition coefficient which is the ratio of the concentration at liquidus and solidus is not constant during solidification, a special integration is carried out to calculate the solidification path, i.e. the solid fraction versus temperature [20]. The assumptions of the Scheil Gulliver approach are considered, i.e. solute concentration at the solid liquid interface is given by the equilibrium phase diagram, no solute diffusion occurs in the solid phase and perfect solute mixing exists in the liquid phase [1]. Figure 5 shows the calculated solid fraction versus temperature for the Al-Zn $6.2 \mathrm{wt}$ pct. Solidification starts at $650^{\circ} \mathrm{C}$ and ends up at $381^{\circ} \mathrm{C}$ with a very small fraction of eutectic, $0.15 \%$. It should be noticed that $\mathrm{g}_{\mathrm{s}}$ increases very rapidly at the beginning of solidification and reaches $90 \%$ at $634^{\circ} \mathrm{C}$. Then solidification proceeds very slowly to finally finish at the eutectic temperature. This part of the curve is crucial to determine the solid fraction at rigidity.

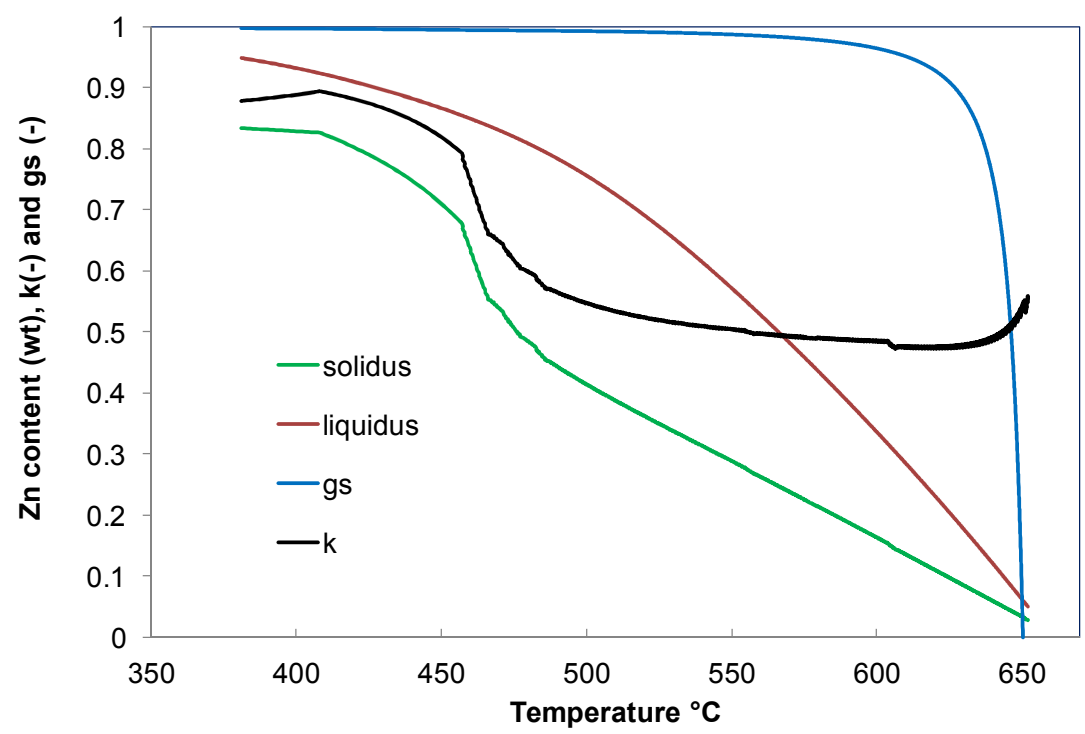

Figure 5: Liquidus and solidus $\mathrm{Zn}$ concentration, solid fraction, $\mathrm{g}_{\mathrm{s}}$, and partition coefficient, $\mathrm{k}$, as a function of temperature in Al-Zn $6.2 \mathrm{wt}$ pct alloys. 


\subsection{Diffraction patterns}

All diffraction patterns were integrated using DAWN software to reduce them to 1D patterns, and TOPAS Academic ${ }^{(}$to retrieve the lattice parameter, using $\mathrm{CeO}_{2}$ powder as a calibration sample. This reduction to 1-dimensional data is justified for samples exhibiting isotropic strain, as is the case here. The lattice parameter of FCC aluminium solid solution at the hot spot located in the gauge volume was extracted. The high temporal resolution allowed us to obtain a sufficient number of diffraction patterns during solidification. The small beam size and small sample thickness allowed us to obtain very clean diffraction patterns leading to weighted profile R-factor (Rwp) in the order of $15 \%$ using LeBail fit [21] and thus small error bars. With an average grain size of $120 \mu \mathrm{m}$ and a gauge volume of $0.5 \times 0.5 \times 7.5 \mathrm{~mm}^{3}$, the number of irradiated grains is approximately 2 '000 thus providing good statistics.

Figure 6 shows the evolution of the lattice parameter and temperature for the three $\mathrm{Al} \mathrm{Zn}$ castings as a function of time. Time is put to zero as soon as the alloy reaches the liquidus temperature. In all three samples, first diffraction patterns are detected as soon as the liquidus temperature is reached. The lattice parameter exhibits first erratic evolution as grains are free to rotate and thus lose Bragg diffraction conditions. As temperature decreases and solid fraction gets close to 0.9, the lattice parameter exhibits some peaks in all samples. Each of those peaks is well defined by many diffraction points. They are associated with the formation and coalescence of grain clusters as reported by Vernède et al. [22] and Sistaninia et al. [23]. As soon as those grain clusters tend to weld together, macroscopic tensile strain develops and leads to the formation of microcracks as shown in figure 3. Stresses and strains are then relaxed and the lattice parameter continues to decrease until the next grain cluster agglomeration/decohesion occurs.

In sample DB2 which exhibited a longer solidification time (cf. fig. 4) and thus a lower cooling rate, the decrease of the lattice parameter is much smoother. Still some small peaks are visible, e.g. at $540^{\circ} \mathrm{C}$. In that sample, more time is provided for the grain clusters to coalesce during solidification but grain cluster agglomeration/decohesion is still noticeable through small and localized cell parameter peaks.

Figure 7 presents the evolution of the lattice parameter and solid volume fraction as a function of temperature for all three $\mathrm{Al} \mathrm{Zn}$ castings. Rigidity temperature is determined as the temperature when the lattice parameter starts to deviate from its linear decrease associated with thermal contraction. This happens at relatively high solid volume fractions where the solute contribution to the lattice parameter is not longer important [20]. Rigidity temperature and volume fraction are schematically represented by vertical lines. In sample DB2, the rigidity temperature is $589^{\circ} \mathrm{C} \pm 4{ }^{\circ} \mathrm{C}$ and corresponds to a solid volume fraction of $97.4 \%$. For both other samples, rigidity takes place later at temperatures of $561{ }^{\circ} \mathrm{C} \pm 5{ }^{\circ} \mathrm{C}$ corresponding to a solid volume fraction around $98.4 \%$.

Experimental findings for each casting are gathered in Table 1 . The lower rigidity temperature found in samples DB1 and DB3 is explained by the lower solidification time, $76 \mathrm{~s}$ and $97 \mathrm{~s}$ compared to $363 \mathrm{~s}$ in sample DB2, and the associated higher cooling rates. Again, time for coalescence is limited and thus rigidity is slowed down. The volume fraction of solid at rigidity determined in the present work agrees with previous studies on coalescence [2] and hot tearing [3,23] in aluminium alloys. The dependence with solidification time is also in accordance with the industrial observation that increasing casting speed increases drastically the risk of hot tearing [1]. 


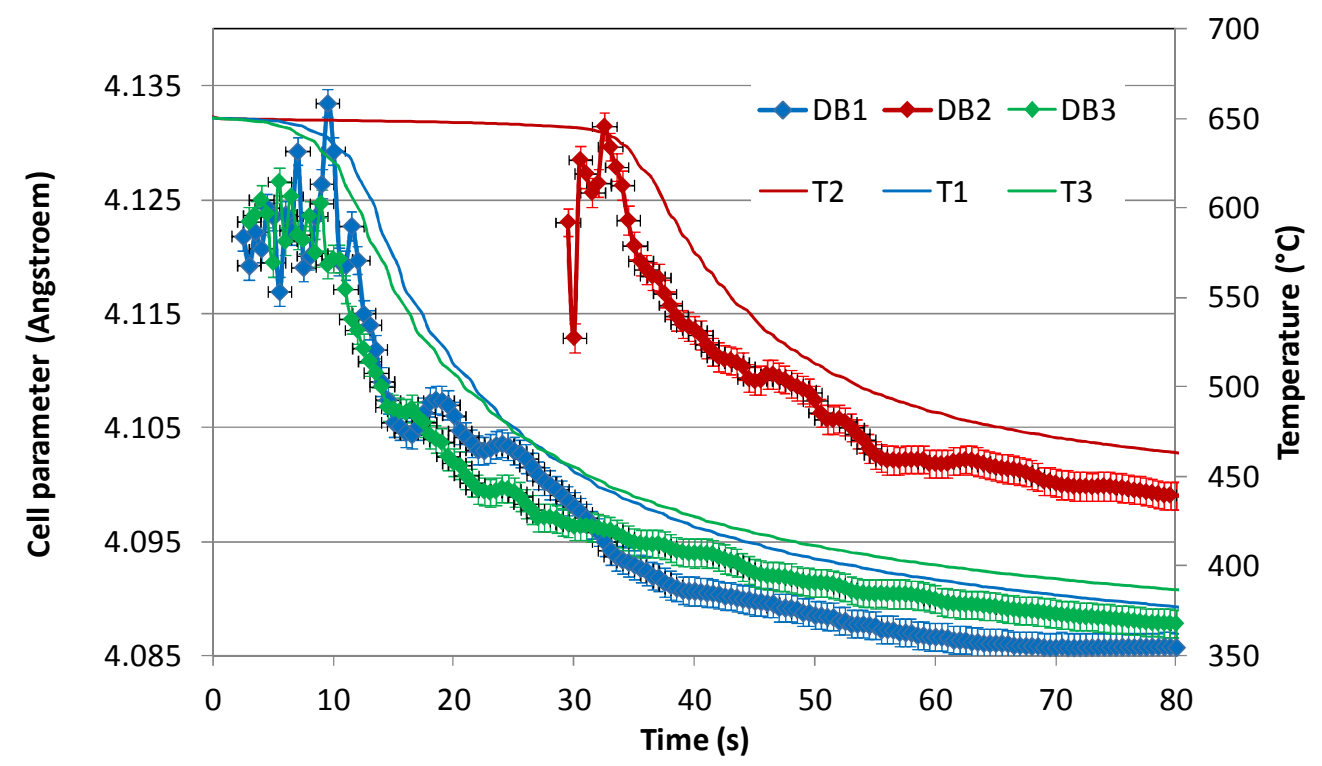

Figure 6: Cell parameter and temperature versus time at the hot spot for all samples.

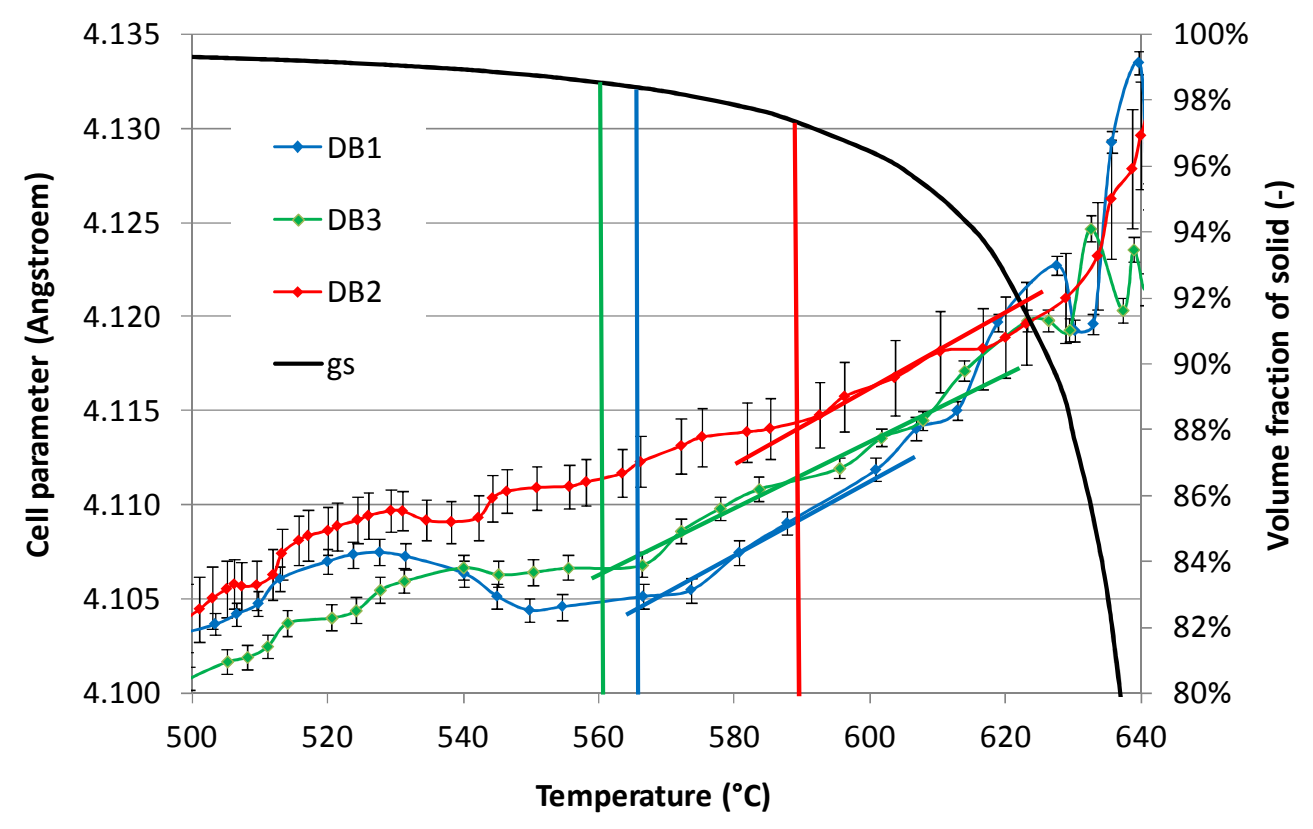

Figure 7: Cell parameter and solid fraction versus temperature at the hot spot and determination of the rigidity temperature for all three samples.

Table 1 Experimental finding for the three Al-Zn samples.

\begin{tabular}{|c|c|c|c|c|c|}
\hline sample & $\begin{array}{c}\text { solidification } \\
\text { time }(\mathrm{s})\end{array}$ & $\begin{array}{c}\mathrm{T}_{\text {mould }} \\
\left({ }^{\circ} \mathrm{C}\right)\end{array}$ & $\begin{array}{c}\text { Average cooling } \\
\text { rate }\left({\mathrm{K} . \mathrm{s}^{-1}}\right)\end{array}$ & $\begin{array}{c}\text { Rigidity } \\
\text { temperature }\left({ }^{\circ} \mathrm{C}\right)\end{array}$ & $\begin{array}{c}\text { Solid fraction at } \\
\text { rigidity }(\%)\end{array}$ \\
\hline DB1 & 76 & 480 & -3.6 & $556-566$ & 98.4 \\
\hline DB2 & 363 & 540 & -0.7 & $585-593$ & 97.4 \\
\hline DB3 & 97 & 468 & -2.8 & $556-566$ & 98.4 \\
\hline
\end{tabular}

\section{Conclusion}

Rigidity temperature has been determined in $\mathrm{Al}$ Zn $6.2 \mathrm{wt}$ pct alloys using in situ X-ray diffraction during casting in a dog bone shaped mould. With a time resolution of $0.5 \mathrm{~s}$, the evolution of the diffraction patterns reveals the presence at high solid volume fractions of small peaks that are explained by the formation of macroscopic strains and stresses that are relaxed by the nucleation of micropores and hot tears. At the grain level, this corresponds to a succession of agglomeration/decohesion between grain clusters. Rigidity temperature and solid volume fraction 
depend strongly on solidification time. The volume fraction of solid at rigidity increases from $97.4 \%$ with a solidification time of $363 \mathrm{~s}$ to $98.4 \%$ with solidification times around $86 \mathrm{~s}$. These findings agree with previous studies on coalescence and hot tearing in aluminium alloys and should be extended to industrial alloys.

\section{Acknowledgments}

The authors express their deep acknowledgements to the Swiss National Science Foundation, Bern, for funding (Project No. 200021_146879) and the Diamond Light Source, Oxfordshire, UK, for the provision of beam time. O. Magdysyuk and M. Drakopoulos, beam scientists at the ID12 beam line at the Diamond Light Source are greatly acknowledged.

\section{References}

[1] Danzig, J.A.; Rappaz, M. Solidification, Defects; EPFL Press: Lausanne, Switzerland, 2009.

[2] Rappaz, M.; Jacot, A.; Boettinger, W.J., Met. Mat. Trans. A 2003, 34, 467-479.

[3] Rappaz, M.; Drezet, J.-M.; Gremaud, Met. Mat. Trans. A 1999, 30, 449-455.

[4] Stangeland, A.; Mo, A.; M'Hamdi, M.; Viano, D. and Davidson, Met. Mat. Trans. A 2006, 37, 705-714.

[5] Terzi, S.; Salvo, L.; Suery, M.; Limodin, N.; Adrien, J.; Maire, E.; Pannier, Y.; Bornert, M.; Bernard, D. and Felberbaum, M.; Scripta Mater. 2009, 61, 449-452.

[6] Suéry, M.; Terzi, S.; Mireux, B.; Salvo, L.; Adrien, J.; Maire, E. Fast, JOM 2012, 64, 83-88.

[7] Phillion, A.B.; Hamilton, R.W.; Fuloria, D.; Leung, A.C.L.; Rockett P., Connolley, T.; Lee, P.D., Acta Mater. 2011, 59, 1436-1444.

[8] Gourlay, C.M.; Dahle, A.K.; Nagira, T.; Nakatsuka, N.; Nogita, K.; Uesugi, K.; Yasuda, H., Acta Mater. 2011, 59, 4933-4943.

[9] Giraud, E.; Suéry, M.; Coret, M., Met. Mat. Trans. A 2010, 41, 2257-2268.

[10]Limodin N., L. Salvo, E. Boller, M. Suéry, M. Felberbaum, S. Gailliègue, K. Madi, Acta Materialia 57 (2009) 2300-2310.

[11] Terzi S., J.A. Taylor, Y.H. Cho, L. Salvo, M. Suéry, E. Boller, A.K. Dahle, Acta Materialia 58 (2010) 5370-5380.

[12]Drezet, J.-M.; Evans, A.; Pirling, T.; Pitié, B., Int. J. Cast Met. 2012, 25, 110-116.

[13] Drezet, J.-M., Pirling, T., J. Mater. Process. Technol. 214 (2014), 1372-1378.

[14] Chobaut N., Repper J., Pirling T., Carron D. and Drezet J-M.: Residual stress analysis in AA7449 as-quenched thick plates using neutrons and FE modelling, 13th International Conference on Aluminum Alloys (ICAA13), Edited by: Hasso Weiland, Anthony D. Rollett, William A. Cassada, TMS (The Minerals, Metals \& Materials Society), 2012, 285-291.

[15] Chobaut N.; Michel, G., Saelzle P., Carron D., Drezet J.-M., Quench induced stresses in AA2618 forgings for impellers: a multi-physics and multi-scale problem, submitted to Journal of Metals, TMS, August 2015.

[16] Drezet J.-M., Mireux B., Szaraz Z., Pirling T.: In situ Neutron Diffraction during Casting: Determination of Rigidity Point in Grain Refined Al-Cu Alloys. Materials 2014, 7, 1165-1172, http://www.mdpi.com/1996-1944/7/2/1165

[17]Diamond Light Source, Oxfordshire, UK, JEEP web site http://www.diamond.ac.uk/Beamlines/Engineering-and-Environment/I12.html

[18]Lalpoor, M., Eskin D.G., Katgermann, L., Met. Mater. Trans. A 2009, 40, 3304-3313.

[19] Alloy phase diagrams, ASM handbook, vol. 3, ASM, 1992.

[20]Drezet, J.-M, Mireux B, Magdysyuk O. and Drakopoulos M., submitted to Met. Mater. Trans. A.

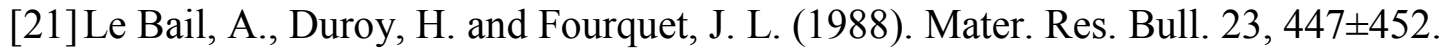

[22] Vernède S., Jarry P., Rappaz, M., Acta Mater. 2006, 54, 4023-4034.

[23] Sistaninia, M.; Phillion, A.B.; Drezet, J.-M.; Rappaz, M.,. Acta Mater. 2012, 60, 3902-3911.

[24] Li S., Sadayappan K. and Apelian D., Int. J. of Cast Metals Research, vol. 24 (2), 2011, p. 88-95. 